\title{
LA PRIMERA REACCIÓN DEL ESTADO ESPAÑOL A LA APARICIÓN DE RUSIA COMO UNA GRAN POTENCIA. Instrucciones de Felipe $V$ al conde de Bena, ministro plenipotenciario en Rusia (1741)
}

\author{
por \\ MARIAN KOVÁCS \\ Universidad «József Attila» de Szeged, Hungría.
}

RESUMEN: El trabajo analiza un documento - ya publicado pero basta abora pasado por alto o desestimado por los investigadores- con el fin, por una parte, de precisar y patentizar unos detalles del tema. Por otra parte, el estudio pone de relieve un becho que se desprende de las instrucciones dadas por Felipe $V$ al conde de Bena, el becho fue que los primeros dirigentes de la politica exterior de España eran capaces de percibir un nuevo elemento de la realidad politica de los años 1740-41, la de la aparición de Rusia como gran potencia, cuando este becho bistórico todavía estaba en el estado de ponerse de manifiesto. Tal vez este reconocimiento motivara a ellos en su intento de restablecer las relaciones diplomáticas con el estado ruso en el contexto del conflicto continental actual, la Guerra de Sucesión de Austria.

PalABRAS ClAVE: España. Rusia. Siglo XVIII. Relaciones diplomáticas. Guerra de Sucesión de Austria.

ABSTRACT: This paper analyses a document which has not been considered adequately by researcbers. The aim of this paper is dual: firstly, to make unambiguous some details concerning the topic. Secondly, it unveils the fact that -as can be detected from the instructions by Pbilip $V$ to count Bena- the leaders of the Spanish foreign affairs as early as in 1740-41 were able to perceive a new element of contemporary political reality, that is the appearance of Russia as a Great Power when this fact still was not so evident. Perbaps this recognition motivated Spain to make a repeated attempt to establisb direct Spanisb-Russian diplomatic inter-state relations in connection with the actual European continental conflict, the Austrian War of Succession.

KEY WORDS: Spain. Russia. 18th century. Diplomatic relations. Austrian War of Succession.

1.i.pania, LIX/2, núm. 202 (1999) 565-586 
PREFACIO

Durante los estudios e investigaciones realizados en la historia de las relaciones diplomáticas hispano-rusas del siglo 18 ha llamado nuestra atención un documento interesante que consideramos digno de un análisis más profundo por tres motivos. Uno de ellos es que, de un modo interesante, los investigadores españoles o dedicados a la bistoria de España basta abora ban pasado por alto o ban desestimado este incidente, pues no hemos encontrado ninguna referencia respecto a ello en la bibliografía española ". Otro motivo es que a base de los resultados de este análisis documental nos atrevemos a precisar y matizar una opinión aceptada en la literatura especializada. Por fin, como tercer motivo, mencionamos la necesidad de aclarar una cuestión cronológica, la del reconocimiento del título de emperador de los zares por parte de España, a veces erróneamente presentada en publicaciones.

La elección del tema se explica todavía por la fecha del documento (30 de mayo de 1741), año inicial de la Guerra de Sucesión de Austria, en el que el conocimiento de los intereses diplomáticos de la corte española en restablecer su correspondencia oficial con la corte zariana ofrecerá mayor posibilidad para interpretar los fines y medios de la política exterior de Madrid en los primeros meses del nuevo conflicto europeo.

\section{EL RESTABIECIMIENTO DE LAS RELACIONES DIPLOMATICAS HISPANO-RUSAS CON EL ADVENIMIENTO DE CARLOS III AL TRONO ESPAÑOL}

\section{Una cuestión cronológica}

En la literatura especializada se acepta la opinión de que a consecuencia de percibir el desplazamiento del eje de las relaciones internacionales, y sus consecuencias para España, causado por la realización de la alianza franco-austriaca

* Los historiadores españoles que sc ocupaban de la trayectorja de las relaciones diplomáticas hispano-rusas en el siglo 18 no indicaron la misión del conde de Bena. Véase: José María SAnciez Dinna, España y el Norte de Europa durante la Revolución Francesa, en Estudios y Documentos. Cuadernos de Historia Moderna, Vol. 21, Universidad de Valladolid Facultad de Filologia y Letras, 1963, págs. 9-20.; Ana María Sci Iop SolıiR, Las relaciones entre Españay Rusia en la época de Carlos IV, Barcelona, 1971, págs. 7-21.; Ana María SCI Iop Sor.ıR, Un siglo de las relaciones diplomáticas y comerciales entre España y Rusia, 1733-1833, Madrid, 1984, págs. 23-42.; Juan HisNANDI:Z FRANCO, Una alternativa al organigrama de las relaciones exteriores de España durante el siglo XVIII, en Aspectos de la politica exterior de España en la época de Floridablanca, Real Academia Alfonso X el Sabio, Murcia, 1992, págs. 129-145.; Sólo dos investigadores rusos mencionaron la misión de Bena. Véase: MGjail AJ.EKSíI:V, Rusia y España - wha respuesta cultural, traducción y prólogo de José Fernández Sánchez, Madrid , 1975, pág. 43.; «V.A. Ulianitskii, Russkie konsulstva..., págs. 152-153.» (La referencia bibliográfica se encuentra en: AJ.rkskiliv, op. cit., pág. 186, nota 75 .)

Hitpathid. LIX/2, núm. 202 (1999) 565-586 
posteriormente llamada revolución diplomática de $1756^{1}$, sólo el primer gobierno de Carlos III reaccionó a la aparición de Rusia como una gran potencia ${ }^{2}$, restableciendo relaciones diplomáticas con ella en 1762. En el fondo, nos ponemos de acuerdo con esta afirmación, pero quisiéramos, por una parte, precisarla, por otra parte, matizarla. Precisarla porque Pedro Luján Jiménez Góngora y Silva, el marqués de Almodóvar y Ontiveros, ministro plenipotenciario acreditado a la corte de Rusia ya entre 26 y 30 de junio de 1761 , llegó a San Petersburgo donde - a causa del estado grave de Isabel I- esperaba su primera audiencia hasta el día 3 de septiembre del mismo año ${ }^{4}$. El enviado ruso, el príncipe Pëtr Repnin ${ }^{5}$ fue nombrado con anterioridad pues a eso aludió el edicto de la zarina Isabel fechado el 15 de julio de $1760^{6} \mathrm{y}$ las Instrucciones a Repnin se firmaton el 11 de agosto del mismo año ${ }^{7}$. Todos estos detalles cronológicos apoyan la afirmación de que los contactos interestatales hispanorusos no se restablecieron en 1762 sino en 1761.

\section{Un acontecimiento importante: el nombramiento del conde de Bena}

A matizar nos instigan los resultados del análisis de las Instrucciones de $\mathrm{Fe}-$ lipe V (1713-1746) y su ministro de Estado y Asuntos Exteriores, Sebastián de la Cuadra (1736-1746) a Don Jacinto Guido Ferrero Fiesco, conde de Bena y Maserán, nombrado ministro plenipotenciario cerca de la zarina, fechadas el 30 de mayo de 1741 en Aranjuez ${ }^{8}$.

1 D. B. HorN, La revolución diplomática, en E/ Antiguo Régimen (1717-1763). Historia del mundo moderno... bajo la dirección de George Richard Potter (y otros), traducción: María Casamar Pérez (Revisión y presentación de la edición española: Juan Reglá), T. VII, Ramón Sopena, Barcelona, 1972, págs. 316-331.

2 Schop Sol.ER, op. cit., 1971, pág. 19,; Emilio BEI,ADIEz, Dos españoles en Rusia. E/Marqués de Almodóvar 1761-1763 y Don Juan Valera 1856-1857, Editorial «Prensa Española», Madrid, 1969 , pág. 26.

3 Hernández Franco, op. cit., pág. 131.

4 Correspondencia diplomática del Marqués de Almodóvar cerca de la córte de Rusia 1761-1763, en adelante Correspondencia, en Colección de Documentos Inéditos para la Historia de España por el Marqués de la Fuensanta - D. José Sancho Rayón - D. Francisco Zabalburu, (en adelante CODOIN), T. CVIII, Imprenta de José Perales y Martinez, Madrid, 1893, págs. 4., 27-28., 55.; Nuestra aserción sobre la fecha de 1761 coincide con la de Beladiez. Véase: BEI.ADtEz, op. cit., págs. 27., 31.

Aquí quisiéramos indicar que, en cuanto a la transcripción del ruso al español, seguiamos las normas de la obra siguiente: J. CALONGE, Transcripción del ruso al español, Gredos, Madrid, 1969.

" Edicto de la zarina Isabel, en Corpus Diplomático Hispano-Ruso (1667-1799), en Biblioteca Diplomática Española, Sección Fuentes, núm. 2, T. I, Ed. Manuel Espadas Burgos, Madrid, 1991, doc. 58 , pág. 128 .

7 Instrucciones del Colegio de Asuntos Exteriores al Printipe Piotr Repnin, Embajador de Rusia en Madrid, en Corpus Diplomático Hispano-Ruso, doc. 59, págs. 129-134.

81741 Instructión dada en 30 de Mayo al Ministro Plenipotenciario de S.M. en Rusia. Conde de Bena, en Archivo Histórico Nacional (en adelante AHN), Sección Estado, Leg. 3455 (En el Appéndice presentamos su fotocopia.); En forma publicada véase: Instrucciontes de Felipe $V$ al Conde de 
Sobre el conde de Bena no sabemos mucho. Fue militar y diplomático quien en 1741 servía a su rey como jefe de escuadra de la Real Armada. Luego «...tuvo su nombramiento de Embajador de España a Sajonia, pero por ser el elector al mismo tiempo el Rey Augusto III de Polonia, representó también a España en esta nación por los años 1745 y $1748 .{ }^{\circ}$. Indica la importancia de su persona el hecho de que Zenón de Somodevilla, matqués de la Ensenada, secretario de Estado de Hacienda (desde 20 de febrero de 1741) y secretario de Guerra, de Marina e Indias (1743-1754) creó para el conde de Bena el título de director general, colocándolo así a la cabeza de la jerarquía modernizada de la Real Armada ${ }^{10}$ donde serviría entre 1749 y 1750.

\section{Contactos diplomáticos bispano-rusos antes del siglo 18}

Si las Instrucciones a Bena las instalamos en la historia de los contactos diplomáticos hispano-rusos, nos encontramos con la segunda ocasión cuando el estado español nombró a un ministro cerca del soberano ruso. En los siglos anteriores al 18 «...en Moscú estaban lejos de conocer la lengua y la literatura españolas, los problemas políticos, la geografía y la gente de España.... Pero Madrid no sabía mucho más de Moscovia.»". Aunque los dos pueblos se conocieron en la esfera interestatal por misiones esporádicas y fuera de ella por noticias vagas, la importancia de estos conocimientos no se puede exageratla.

Sin embargo, las descripciones de los viajetos al otro pais, las noticias de los rusos cautivos de los tártaros de Crimea que llegaron a su tierra natal por España, los informes sobre el establecimiento de la Inquisición en España, el descubrimiento de América, los caprichos horribles de Ivan IV el Terrible, las luchas sangrientas entre los años 1604 y 1613 por el trono de los zares y el conocimiento de unas obras de la literatura española constituyeron el trasfondo de las relaciones interestatales hispano-rusas comenzadas en el siglo 16 que principalmente se concentraban en la lucha común contra los otomanes y los tártaros ${ }^{12}$. Estas relaciones diplomáticas, derivadas de las entre el Sacro-Imperio Romano y el Gran Principado de Moscú, se representaron por la corres-

Bena, stombrado Ministro Plenipotenciario en Rusia, en adelante Instrucciones, en Corpus Diplomático Hispano-Ruso, doc. 55 , págs. $120-125$.

9 Comte Renaud PRZLzZDZILCKI, Diplomatie et protocole a la cour de Pologne. Embajadas españolas de/ siglo XVIII, en Boletín de la Real Academia de la Historia, T. CXIII (1948), pág. 353.

10 La modernización se realizó en 1748 por las Ordenanzas generales de la Armada. Véase: Didier Ozanan, La política exterior de España entre la Paz de Utrecht y el tercer pacto de familia, en La época de los primeros Borbones. Historia de España de Ramón Menéndez Pidal dirigida por José María Jover Zamora, T. XXIX, Vol. I, Espasa-Calpe, Madrid, 1985, pág. 477.

11 ALEKSÉEv, op. cit., págs. 38-39.

12 AI..KSÉEVV, op. ait, págs. 13-26.; Friedrich ADEJ.UNG, Kititisch-literärische ẅbersicbt der Reisenden in Russland bis 1700, deren Bericbte bekannt sind, T. I, Amsterdam, 1960, págs. 85-87.; ADEJ,UNG, op. cit., 126; ADIIung, op. cit., T. II, pág. 297; Gyula Szvík, Mosqéótia és a Nyugat, Budapest, 1988, págs. 84-85., 87-89., 90., 92-93.; Gyula Szvík, Cárok és kalandorok, Budapest, 1982, págs. 110-111.

Hi.punic, LIX/2, núm. 202 (1999) 565-586 
pondencia oficial entre Carlos V y Vasiliii IV e Ivan IV, Felipe II e Ivan IV (en $1523,1525,1535,1548,1552,1556$ y 1570) ${ }^{13}$. Desde 1585 la guerra contra los turcos se relegó a segundo plano en la política exterior de la monarquía católica de Felipe II y este hecho junto con problemas financieros significó el abandono de la colaboración entre los dos estados, en cuanto a sus contactos diplomáticos ${ }^{14}$.

En la segunda mitad del siglo 17 fue el Imperio Ruso que tomó la iniciativa para restablecer las relaciones hispano-rusas como parte de su programa de mejorar sus contactos con las cortes europeas, es decir, de abritse hacia el resto de Europa ${ }^{15}$. Misiones rusas se presentaton en la corte española en 1667,1672, 1680 y 1688 con la finalidad de que le informaran sobre los asuntos interiores y exteriores de Moscovia, que le demostraran su poder engrandecido por la anexión de Ucrania y la extensión en Siberia, que le propusieran un tratado comercial y, sobre todo, que obtuviera de ella una alianza antiturca ${ }^{16}$. En cuanto a la respuesta del estado español, ésta fue determinada por la crisis de la región mediterránea en su conjunto, la de Castilla y su situación marginal en la Europa moderna a la que relegó a España «...el reordenamiento ideológico en torno a valores que se impusieron poco a poco sin la colaboración de España, contra la voluntad de España.) ${ }^{17}$. Pues «el gigante con los pies de barro" ${ }^{18}$ se comportaba cortés y amistosamente con los enviados rusos, pero le negaba el cumplir sus peticiones y dedicó sus propias energías a la renovación de sus fuerzas internas.

\section{Relaciones interestatales bispano-risas en el siglo 18}

Con el siglo 18 empezó una nueva época en las relaciones diplomáticas hispano-rusas. Se inició una nueva época porque, por una parte, a nivel de los principios del sistema de las relaciones diplomáticas internacionales ocurrió un cambio: cambio del principio de la hegemonía al del equilibrio ${ }^{19}$. Por otra par-

13 John PAXTon, Companion to Russian History, New York, 1983, pág. 48.; SClyOr Soler, op. cit., 1984, págs. 23-24.; Corpus Diplomático Hispano-Ruso, págs. 3-4, nota $3^{3}$; Antonio Dominguiz. OrTiz, El Antiguo Régimen: Los Reyes Católicos y los Austrias, en Historia de España dirigida por Miguel Artola, T. 3, Alianza Editorial, Madrid, 1988, pág. 71.

14 H. LAPEYRE, Las etapas de la politica exterior de Felipe II, Valladolid, 1973.; Joseph PÉREZ, España moderna (1474-1700). Aspectos políticos y sociales, en Jean Paul Le Flem — Joseph Pérez - Jean-Marc Pelorson - José Maria López Piñero - Janine Fayard, La frustración de un imperio (1476-1714). Historia de España dirigida por Tuñon de Lara, T. 5, Editorial Labor, S.A., 1989, págs. 193-195.; DOMINGUEz OR'TZ, op. cit., pág. 88.; SzVÁk, op. ait., 1988, 84-85., 87. 158.

15 Michael Thimothy FlorinsKy, Russia. A Short History, London, 1971, págs. 133., 155

16 Constantin Derjavine, La primera embajada rusa en España, en Boletin de la Real Academia de la Historia, T. 96 (1930), págs. 877-896.; Los documentos más importantes de este período véase: Corpus Diplomático Hispano-Ruso, docs. 1-22., págs. 3-51.

17 PÉREZ, op. cit., págs. 221-222.

18 Emplea la expresión: José Calvo, La Guerra de Sucesión, Anaya, Madrid, 1988, págs. 9-10.

Hizpania, L.IX/2, núm 202 (1999) 565-586 
te, a nivel ideológico la europeización de Rusia significó el ensanchamiento de la idea de Europa ${ }^{20}$. Y de parte de los intereses, había novedad que el punto común en la posible colaboración entre España y Rusia ya no fue la lucha contra los otomanes, sino los esfuerzos para restablecer y mantener la correspondencia oficial se dirigian a hacer valer los propios fines políticos en alianza con la otra potencia.

Dentro del siglo 18 el período entre 1715 y 1732 lo consideramos como una unidad en la cual la muerte del zar Pedro I significa una ruptura, pues desde 1715 y 1725 Pedro el Grande hizo relativamente grandes esfuerzos con el fin de aproximarse de nuevo a España ${ }^{21}$. Sus esfuerzos se caracterizaban por dos objetivos. En primer lugar mencionamos - porque éste parece más fuerte y más persistente- el objetivo económico del soberano ruso ${ }^{22}$, según el cual Pedro, estableciendo relaciones comerciales con España, quería adquirir una parte de los metales preciosos de las Indias que llegaban a Cádiz para que estos metales junto con la riqueza fabulosa de los países medio-otientales de Asia contribuyeran al desarrollo económico de Rusia. Por eso mismo ordenó hacer proyectos sobre el comercio hispano-ruso e inició una serie de medidas (1723) y como consecuencia se estableció el consulado ruso en Cádiz (1724), se formó una pequeña colonia de comerciantes rusos también en Cádiz y comenzó el tráfico de mercancías entre los dos países (1725). En segundo lugar mencionamos el intento diplomático del zar que, en conformidad con los fines de su política exterior, entre 1717 y 1719 buscaba la alianza española para equilibrat la alianza sueco-inglesa, hostil con él ${ }^{23}$. Como es obvio, en los primeros decenios del siglo 18 fue Rusia que tomó la iniciativa en las relaciones diplomáticas hispano-rusas y este papel de iniciador reflejaba bien el carácter ascendente de su condición entre las potencias europeas.

La corte española en 1717-1718 reaccionó por primera vez a los intereses comerciales y políticos de Rusia cuando el cardenal Alberoni (1664-1752) consideró la posible alianza de España con Rusia como medio conveniente para modificar los artículos de la Paz de Utrecht (1713) dañosos a los Borbones es-

19) José Maria Jover Z ZMORn-Elena HeINŃNDEZ, SANDOICA, España y los tratados de Utrecht, en La época de los primeros Borbones. Historia de España de Ramón Menéndez Pidal dirigida por José María Jover Zamora, T. XXIX., Vol. I, Espasa-Calpe, Madrid, 1985, págs. 343-350.

20 Leibnitz, en sus últimos años, a base de criterios culturales definió la idea de Europa en que incluyó también a Rusia. Véase: Gaston Zrill. Relaciones Internacionales dirigida por P. Renouvin, T. I, Madrid, 1967, págs. 636-637.; Sর́NCIIEZ DianA, op. cit., págs. 10-11., nota $2^{\mathrm{a}}$; En esta nueva Europa San Petersburgo fue una cabeza de puente. Véase: Julián Marlas, La España posible en tiempo de Carlos III, Editorial Planeta, S.A., Barcelona, 1988, págs. 17-18.

21 Los documentos más importantes de estos años véase: Corpus Diplomático Hispano-Ruso, docs. 23-41., págs. 51-84.

22. T. K. KRYlov^, Otnosheniia rossii i ispanii v pervö̈ chetverti XVIII veka, en Sbomik Kultura Ispanii, Moskva, 1940, págs. 337-352.

23 Claude J. NorDmann, La crise du Nord au début du XVIII siëcle, Paris, 1956, págs. 42-45., 84-90., 147-154., 160-163.

Hipoatia, LIX/2, núm 202 (1999) 565-586 
pañoles ${ }^{24}$. Aparte de las concepciones autónomas de Alberoni en el terreno de la política exterior, en cuanto a la cuestión de un acuerdo comercial con Rusia, el estado español se caracterizaba por un comportamiento cauto y parece que éste fue adecuado a la realidad económica de España de entonces. No cabía duda de que las mercancías rusas de calidad y de un precio más bajo hubieran encontrado mercado en España, pero la economía española, que tenía sus problemas económicos y producía pocas mercancías capaces de competir, no se atrevió a ofrecer los privilegios permanentemente exigidos por Rusia y sólo según el principio de intercambio podía imaginar el comercio hispano-ruso ${ }^{25}$. Este comportamiento cauto de España en la cuestión de un posible contrato comercial con el Imperio Ruso persistió durante todo el siglo 18 y eso, lógicamente, dificultó la efectividad de su política exterior ${ }^{26}$.

La corte de Madrid trató de tesponder a las iniciativas de la corte zariana con uno de los medios probados de la diplomacia clásica, con proyectos matrimoniales. Por primera vez, en 1723 cuando se establecieron negociaciones sobre el matrimonio del infante Felipe con la hija del Pedro el Grande, la gran duquesa Natalia ${ }^{27}$. Por segunda vez, en 1727 cuando los soberanos españoles tomaron la iniciativa de proponer al zar Pedro II el matrimonio entre el infante Carlos y la gran duquesa Natalia, hermana del $z^{2}{ }^{28}$. Sin embargo, ninguno de los dos pudo realizarse por la razón de la muerte de las grandes duquesas y la transformación de las relaciones de alianza a nivel internacional.

Esta última junto con la salida de los promotores de las relaciones diplomáticas hispano-rusas de la esfera política (la caída de Alberoni el 5 de diciembre de 1719 y el fallecimiento de Pedro I el 8 de febrero de 1725) dificultaron el desenvolvimiento aún el mantenimiento de los contactos ya existentes. Todo eso para el año 1730 hizo insensata la presencia de los diplomáticos (el príncipe I. Shcherbatov y el duque de Liria) en las capitales respectivas.

\section{La misión del conde de Bena}

Después de la salida de Liria desde la corte de Moscú (el 30 de noviembre de 1730) ${ }^{29}$ y la de su secretario, Juan Cascos de Villademoros desde San Peters-

24 OZANan, op. oit., págs. 588., 590-591.; Las referencias húngaras del proyecto de Alberoni véase: Maria Ester BrexTol, I/ cardinale Giulio Alberoni e il principe Francesco II Rákáczí, en Nuova Rivista Storica, 1966.

25 KrYiovs, op, cit., págs. 346-349.

26 Herníndez Franco, op, cit., págs. 14-15.

27 Caria a Pedro I del Ministro Plenipotenciario del Dwcado de Parma, Don Francesco Arcelli, en Cor. pus Diplamático Hispano-Ruso, doc. 33., págs. 67-68.

28 Marian Kovács, "Un prayecto matrimonial olvidado entre los Borbones de España y los Romanov de Rusia a principios deli siglo XVIIn, en Trienio, núm. 25. (1995), págs. 5-32.

2) Diario del viaje del Duque de Liria y Xérica, en adelante Diario, en CODOIN, T. CXIII, M. Ginesta Hermanos, Impresores de la Real Casa, Madid, 1889, pág. 474. 
burgo (en 1732) ${ }^{30}$, hasta 1761 no había contacto oficial directo entre los dos estados ${ }^{31}$. Sólo en 1740-1741, en relación con la Guerra de Sucesión de Austria en fase inicial tomó - de nuevo España- la iniciativa de renovar su correspondencia diplomática con Rusia. La Secretaria de Asuntos Exteriores de España nombró cerca del soberano ruso al conde de Bena a cuyas persona y misión, como ya hemos mencionado anteriormente, se encuentran solamente unas referencias esporádicas.

Sin embargo, nosotros consideramos de importancia las Instrucciones a Bena porque en éstas parece manifestarse que los primeros dirigentes de la politica exterior de España percibieron un nuevo elemento de la realidad politica de aquellos años, la de la aparición de Rusia como una gran potencia y tal vez este «descubrimiento» motivara a ellos en su intento de restablecer las relaciones diplomáticas con ella en el contexto del conflicto continental actual. Todo eso ocurrió, mientras estaban formándose las alianzas y España estaba tomando su posición en la contienda europea. Aunque no había grandes dudas sobre el partido que tomaría España, los responsables del estado español querían conocer la opinión de la corte de San Petersburgo en la cuestión de la Pragmática Sanción e influirla ventajosamente para ella. En suma, el análisis del documento nos permite suponer que ya en los años 1740 y 1741 España reaccionó, por primera ver, a la aparición de Rusia como una gran potencia cuando este becho histórico todania estaba en el estado de ponerse de manifiesto.

Según constata Lindsay, «El desenvolvimiento diplomático del período comprendido entre 1713 y 1740 , que parece, de hecho, a la luz de la historia posterior, haber sido el más importante para el futuro, fue algo que escapó a los observadores contemporáneos, por lo menos hasta el año 1733. ... Lo que iba a ser mucho más importante para el futuro de Europa fue la aparición de Rusia y Prusia como grandes potencias [subrayada por M. K.]. Estos dos estados fueron los vencedores reales de la Guerra del Norte, pero durante los veinte años siguientes, ninguno de ellos estuvo en disposición de seguir una politica independiente y tomat la iniciativa diplomática. Después de la muerte de Pedro el Grande en 1725, Rusia tuvo una serie de cortos reinados - Catalina I (1725-1727), Pedro II (1727-1730), Ana (1730-1740), Iván VI (17401741) - que junto con los caracteres de sus monarcas, las incapacitaron para jugar un papel de efectiva consistencia en los asuntos internacionales.s ${ }^{32}$. Ade-

30 Al empezar el año 1732 la corte de la zarina Ana I volvió desde Moscú a San Petersburgo. Véase: Gyula LAZÁR, Az orosz birodalom történelme, Temesvár, 1891, T. IV, pág. 40.; Los ûltimos despachos de Villademoros proceden también de 1732. Véase: Znachenie Simanskago arjiva dlia rysskoï istorit, en Shmurlo, Rossiia i Italita, en Sbornik Akademii Nauk, Vol. III, Petrograd, 1915, pág. 221.

31 Contactos hispano-rusos indirectos existian sobre todo a través de la diplomacia francesa, napolitana y sueca.

32 J. O. LinDSAY, Relaciones internacionales, en El Antiguo Régimen (1713-1763). Historia del mundo moderno ... bajo la dirección de George Richard Potter (y otros), traducción: Maŕa Casamar Pérez (Revisión y presentación de la edición española: Juan Reglá), T. VII, Editorial Ramón Sopena, Barcelona, 1972, pág. 144.

Higpania, J.IX/2, núm. 202 (1999) 565-586 
más, «Durante algún tiempo, Rusia se inclinó hacia Asia, volviendo la espalda a Europa.s ${ }^{33}$.

Sin embargo, la transformación en la correlación de fuerzas europeas no escapó a la atención del cardenal Fleury quien, terminando la guerra rusa contra Turquía en 1739 hacía esta advertencia: "Con relación al equilibrio del norte, Rusia ha alcanzado un grado de poder excesivo, y su unión con la casa de Austria es extremadamente peligrosa.s ${ }^{34}$. En la historiografia moderna, en cuanto a la relación entre Europa y la potencia rusa, se subraya un acontecimiento militar del año de 1735 cuando durante la Guerra de Sucesión de Polonia (17331738), por primera vez, un ejército ruso penetró profundamente en Europa ${ }^{35}$.

Por lo que se refiere a la fecha de las Instrucciones a Bena ( 30 de mayo de 1741), la Secretaria de Asuntos Exteriores de España ya en 1740 tomó medidas para restablecer sus contactos diplomáticos con la corte zariana. «En un rescripto de 11 de junio [de 1759] ${ }^{2}$ dirigido al antiguo embajador en París, Conde Bestuzhev-Riumin, se dice: Por la correspondencia de los años 1740, 1741 y 1742 , de vuestro difunto ${ }^{2}$ predecesor el Príncipe Antíoco Kantemir, estaréis ya detalladamente informado de que la Corte de Espana, para el establecimiento de una correspondencia [oficial], la consolidación de una buena armonía en común provecho de ambos pueblos, y la firma de un tratado comercial con este Imperio, [se propuso] enviar aquí un Ministro suyo [fue designado el Conde Delven ${ }^{36}$, deseando que, en reciprocidad, de aqui fuera enviado un Ministro a la Corte española ${ }^{37}$ \%.

Desgraciadamente de los documentos no se pone en claro si España habrá tomado la iniciativa de renovar sus relaciones con Rusia antes o después del fallecimiento del emperador Carlos VI (20 de octubre de 1740). Pues este detalle cronológico aclarará el porqué de la intención original de Madrid para renovar sus contactos diplomáticos con San Petersburgo. Es decir, si Madrid habrá

33 ZeLler, op. cit., pág. 662.; En los últimos años de su reinado ya Pedro I prestó atención de nuevo al Oriente (empresas en Georgia y Armenia entre 1722 y 1724). Véase: ZLLLLLR, op. cit., pág. 662.; Una nueva guerra ruso-turca se estalló el 2 de mayo de 1736 que terminó con el tratado de Belgrado el 1 de septiembre de 1739. Véase: Magyarország Törtineti Kronologiaja 1526 1848, T. II, Akadémiai Kiadó, Budapest, 1982, págs. 565., 567.

34 Las palabras de Fleury se citan en: LINDSAY, op. att., pág, 145.

35 Ibidem, pág. 145.; ZELler, op. cit., pág. 659.

36 El conde Delven mencionado en el documento ruso debe ser idéntico con el conde de Bena, pues éste fue nombrado a la corte zariana en 1741 y más tarde, como ya hemos citado las palabras del estudio de Renaud Przezdziecki, fue enviado a la corte sajona y polaca (17451748). Lo mismo está afirmado sobre Delven en la continuación del documento ruso: «Posteriormente [incluyendo el año de 1746 - M.K.], el Conde Delven fue nombrado por su Gobierno Ministro ante la Corte polaca.» Véase: Rescripto acerca del reconocimiento por España en 1759 del titulo de Emperador y sobre el intercambio de Ministros por ambas partes, en adelante Resiripto, en Corpus Diplomático Hispano-Ruso, doc. 57, pág. 127.

37 Rescripto, pág. 126,; Las palabras indicadas con el número 2 están tachadas en el texto original según la nota de la publicación del documento. Las palabras en corchete - seguin el uso- son complementos de los redactores del Corpus Diplomático Hispano-Ruso. 
buscado el contacto con la corte zariana porque estaba motivada por el desenvolvimiento acelerado de los acontecimientos bélicos de la Guerra de Sucesión de Austria, o si habrá intentado restablecer sus relaciones diplomáticas con la corte zariana independientemente de eso, ya antes del surgir el problema de la Pragmática Sanción. Naturalmente en este último caso es obvio que, al morirse Carlos VI, el intento de renovar la correspondencia oficial con el soberano ruso había podido confirmarse. Pues «Los problemas planteados por su sucesión trastocaron todo el tablero diplomático y modificaron profundamente el carácter de la guerra en curso entre España e Inglaterra ${ }^{38}$. Las ambiciones de Isabel Farnesio, desencadenadas de nuevo ${ }^{30}$, el triunfo en Francia del partido militar opuesto a Austria ${ }^{41}$, iban a otorgar una prioridad absoluta a los asuntos europeos, relegando a segundo plano el conflicto marítimo y colonial ${ }^{41} \%$.

Con objeto de asentar las Instrucciones a Bena en el curso de los acontecimientos militares y diplomáticos de la Guerra de Sucesión de Austria quisiéramos hacer hincapié en los siguientes acaecimientos desde el punto de vista de nuestro tema. Pasando en orden cronológico, el primero es que el 16 de diciembre de 1740 ejércitos prusianos entraron en Silesia, sin declaración de guerra ${ }^{42}$. Francia, todavía en el mismo mes, entabló negociaciones preliminares con Federico II ${ }^{43}$ por cuyas resultas el 5 de junio de 1741 se firmó una alianza franco-prusiana ${ }^{44}$. El 10 de abril de 1741 Prusia consiguió una brillante victoria sobre Austria en Molwitz ${ }^{45}$. Felipe V, para procurar tener de su parte a Francia, entró en negociaciones con Baviera y con Cerdeña. Con la primera, Cristóbal Portocarrero y Guzmán, el conde del Montijo, nombrado embajador de Espa-

\footnotetext{
38 Aunque el secretario de Estado, Sebastián de la Cuadra y su colega inglés, Robert Walpole se mostraron poco belicosos y trataron de encontrat salida en torno a la mesa de las negociaciones (acuerdo de principio el 9 de septiembre de 1738, convención del Pardo el 14 de enero de 1739), la Guerra de Jenkins' Ear se estalló entre España e Inglaterra el 19 de octubre de 1739 por tensiones que por mucho tiempo habian quedado sin solución. La guerra, en que desde agosto de 1740 , conservando su libertad de acción, participaron al lado de los españoles escuadras francesas desembocó en la Guerra de Sucesión de Austria. Véase: Ozanan, op. cit., págs. 621-625.

31) El papel y la responsabilidad de la reina Isabel Famesio en la política exterior del reinado de Felipe $\mathrm{V}$ es todavía cuestión discutida en la bibliografía. Sin embargo, no cabe duda de que la parmesiana trató de aprovechar todas las ocasiones ofrecidas por las coyunturas políticas para adquirir dominios para sus hijos —en este caso al infante Felipe- en Italia donde los territorios españoles habian pasado a Austria. Véase: OZANAN, op. cit., págs. 634-635.

40. Fleury de casi noventa años sólo quería «... arrancar el título imperial a la casa de Habsburgo para investir con él al elector de Baviera.» Véase: OzAnAN, op. cit., pág. 625.; Peto él se véa obligado a ceder ante la presión del partido antiaustriaco encabezado por los hermanos de Belle-Isle. A consecuencia de eso fue nombrado como embajador a la dieta electoral de Francfort (1741) el conde de Beile-Isle. Véase: ZliLLER, op. cit., pág. 673.

41 OZANAN, op. cit., pág. 625.

42 Ibidem, pág. 625.; Zlillise, op. cit., pág. 672.

4.3 LiNDSAY, op. cit., pág. 148.

44 OZANan, op. cit., pág. 627.

45 Magyarorsqag Tönténeti Kronológiaja 1526-1848, pág. 568.
}

Hipania, LIX/2, núm 202 (1999) 565-586 
ña en la dieta de Francfort, firmó el tratado de Nymphenburg (Baviera) el 28 de mayo de 1741, «... por el que, mediante la garantía del futuro establecimiento de don Felipe en Italia, Carlos Alberto recibía la promesa de subsidios y de apoyo para la elección imperials ${ }^{46}$.

Teniendo a la vista estos acontecimientos del año de 1741, vamos a estudiar nuestra fuente en cuyo primer apartado se redacta, fuera de la estereotipia de la gran distancia y la falta de los intereses directos entre los dos estados, el reconocimiento del gran influjo y poder de Rusia en Europa como motivo que dirige la atención de los políticos del estado español hacia la potencia rusa. «Aunque la remota situación de la Moscovia, respecto de nuestros Dominios, aleja también los recíprocos intereses de ambas Monatquías, no obstante la glotiosa conducta del Zar Pedro, que extendió los influjos de su poder hasta mezclarse con los negocios más arduos de Europa, en que se han adelantado ventajosamente sus sucesores, nos precisan a mirar aquel Dominio como paraje conveniente ya al adelantamiento de nuestras ideas" ${ }^{47}$.

A continuación, y antes de exponer detalladamente los objetivos diplomáticos de Bena, el documento llama la atención del diplomático español — se trata también de una estereotipia- - a que siga las reglas de la religión católica con mayor puntualidad en el ambiente ortodoxo de la corte rusa. Aquí consideramos de importancia mencionar que las Instrucciones erróneamente hablan del zar Ivan II quien reinaba entre 1353 y 1359 . Probablemente se trata de una errata, pues el zar de entonces fue Ivan VI que, nació el 19 de agosto de $1740^{48}$ y en mayo de 1741 tenía sólo unos meses.

La misión de Bena consistía en lograr realmente un fin diplomático y para poder cumplirlos fue necesario «... inquirir y averiguar la situación interna y exterior de aquella Corte, esto es, el estado de su Gobierno e inquietudes y el de su seguridad o recelo de los Príncipes confinantes; ... Al mismo tiempo, os aplicaréis a descubrir el genio y cualidades de la Regente de aquel Imperio y las de su marido, el Duque de Brunswick, las del Barón de Ostermann, alma de aquel vasto cuerpo, como el primero y más hábil entre los Ministros que le rigen, y las de los generales Munich y Laski, que tanto representan por las numerosas tropas que gobiernan. Y no sólo habéis de indagat lo que privativamente corresponde a la condición y disposiciones de cada uno, sino también el enlace relativo que haya entre ellos, así por lo que mira a los actuales manejos de aquella Corte y Monarquía, como por la concerniente a las esperanzas e ideas que tengan de por sí o todos juntos» ${ }^{49}$.

Resulta de la cita que en Madrid tenían informaciones exactas quiénes fueron los que efectivamente gobernaron los asuntos del estado ruso. La pareja regente, Ana Leopoldovna Karlovna, sobrina de la zarina Ana I y su marido, el príncipe de Braunschweig-Lüneburg, Anton Ulric que fueron llamados a la

\footnotetext{
Ozanan, op. cit., págs. 626-627.

Instrucciones, pág. 121.

48 LÁź́x, op. cit., pág. 69.

4) Istructiones, pág. 121.
} 
corte por Ana I para asegurar la sucesión de los Romanov y que ascendieron al poder después de la caída de Biron ${ }^{50}$ (20 de noviembre de 1740).

Al lado de los regentes el barón de Ostermann que de un bajo funcionario alemán sencillo y diligente de Pedro I llegó a ser durante el reinado de Catalina I vicecanciller (1725), luego confidente de Pedro II y bajo el teinado de Ana I, siguiendo como vicecanciller, influyó definitivamente en la política exterior de Rusia ${ }^{51}$, y así, como el documento dice, llegó a ser realmente «el alma de aquel vasto cuerpo». Fuera de Ostermann, el diplomático español tendría que enterar a Sebastián de la Cuadra sobre los generales Münnich y Lacy. En su caso se trata de dos militares extranjeros cuya carrera llegó a su cenit durante el reinado de Ana I. La modernización del ejército ruso en los años treinta se debe a la persona del general Münnich quien desde 1732 fue presidente del Consejo de Guerra y en la guerra con Turquía (1736-1739) obtuvo grandes triunfos y se debió a él la carda de Biron ${ }^{52}$. El general Lacy de procedencia irlandesa sobresalió en las guerras de Sucesión de Polonia y contra Turquía y varias reformas militares se deben a su actividad ${ }^{53}$. Por lo demás, en Madrid ya sabian algo de Ostermann, Münnich y Lacy supuesto que el duque de Liria en sus despachos ofrecía informes sobre ellos y también les dedicó unas líneas en su Tratado particular de caracteres ${ }^{54}$.

Lo que corresponde al enlace entre las personas anteriormente mencionadas, el cuadro es bastante complejo. Los miembros del "partido alemán" que ocuparon los altos puestos del estado ruso se rivalizaron. Münnich y Ostermann ya desde tiempo se consideraron como enemigos ${ }^{55}$. Discordias dividieron a la pareja regente, pues la regente Ana seguía teniendo, relaciones íntimas con el conde de Lynar, enviado de Sajonia a la corte rusa. Él, junto con la baronesa Julieta Mengden, hermana de Ostermann y pariente de Münnich y el marqués de Botta, ministro de Austria en la corte zariana, influyeron en la regente que no tenía experiencias en la gobernación. El príncipe Antonio Ulric,

50 Ernst Johann Bühren llegó a Rusia en 1714. Desde 1727 fue el favorito de Ana, entonces duquesa de Curlandia. Véase: PAXION, op. cit., pág. 57.; Al juicio de Lázár, Ana y Biron ya desde 1724 tenian relaciones intimas. En la corte zariana, en los primeros tres años del reinado de Ana I Biron no se metió en los asuntos estatales, pero en los siete años restos el poder se encontró en manos de Biron. Véase: LÁÁr, op. iit., pág. 56.; Ana I en su testamento (17 de octubre de 1740) nombró "... como regente a Biron, a quien elevó al rango de príncipe de Kurlandia [en 1737 - M. K].» Véase: PL.AYONOv, Historia de Rusia, Buenos Aires, 1943, págs. 177-178.; En la bibliografía se emplea el término de Bironismo para nombrar los años del gobiemo cruel de Biron en que se estableció un verdadero servicio de espionaje. Véase: Nicolas V. Riasanovsky, A History of Rassia, Oxford University Press, New York Oxford, 1984, pág. 245.

51 Constantin de Grunwaid, Ostermann et le «tegne des Allemands», en Trois siècles de Diplomatie Russe, Calmann-Lévy, Éditeurs, Paris, 1945, págs. 45-67.

52 LAZÁr, op. cith, págs. 39-45., 47., 50., 52-53., 76-79.

53 PAXTON, op. cit., pág. 57.

54 Dianio, págs. $365 ., 370$.

55 LA\%Á, op. cit., pág. 50.

Hi.punia, LJX/2, núm. 202 (1999) 565-586 
generalísimo y regente, encontró partidarios contra las ambiciones de Münnich, entre otros, en Ostermann ${ }^{56}$.

Al descubrir el entedo complicado de estas vinculaciones pudo empezar Bena a cumplir el fin principal de su misión «... saber la fuerza y vigor en que se considera allí a la Pragmática Sanción .... ${ }^{57}$. Las Instrucciones, en estrecha relación con las rivalidades ocurridas en la corte rusa por el poder, tenían en cuenta tres actitudes posibles del Colegio de Asuntos Exteriores de Rusia para el futuro.

1. «No serán hoy los ingleses y Holanda, cuando se declare a favor de la Gran Duquesa [María Teresa de Austria - M.K.], como garantes que son de la Pragmática Sanción, los que menos soliciten interesar al Zar en la querella común; y en este caso, seguiréis los pasos de los Ministros que mantienen en aquella Corte, para descubrirlos y embarazarlos, según cupiere en la oportunidad y en las circunstancias》 ${ }^{58}$.

2. «Cuando halléis que aquel Ministerio no se empeña en sostener la Pragmática Sanción y que antes bien apoya en algún modo a los que la contradicen, os introduciréis a proponer un tratado de comercio, para que por este camino atar algunos pactos que favorezcan nuestras operaciones en la actual coyuntura de Europa; que aunque hasta ahora mantienen más cuerpo que el de la negociación, es natural que no permanezcamos así largo tiempo y que aún, sin nuestro informe, el ruido de ellas os preste asunto para acalorar este pensamiento" ${ }^{5 \%}$.

3. «...; y en fin, si no pudiere entablarse nada de esto, a lo menos cabe el pedir una neutralidad que nos será muy útil, pues le faltarán al Gran Duque [Francisco de Lotaringia - M.K. ${ }^{60}$ ] unos socorros muy considerables en la triste situación en que le tienen sus muchos enemigos y pocos haberes ${ }^{61}$ ).

Por una parte, en las citas se manifiesta que en la corte rusa en mayo de 1741 había dos partidos opuestos en la cuestión de la Pragmática Sanción. El príncipe Antonio Ulitic y Münnich se inclinaton a una alianza con Prusia y, aceptando la propuesta de Federico II, antes de la invasión de Silesia firmaron con él una alianza «... en cuyo sentido las dos potencias se empeñaron en ayudarse de obra en todo, a excepción las guerras con Persia y Turquía.» ${ }^{62}$. Sin em-

56 Ibidem, op. cit., págs. 79-81.

57 Instrucciones, pág. 122.

58 Instructiontes, pág. 123.

59) Instructiones, pág. 122

(n) Con mucha probabilidad se trata del gran duque Francisco de Lotaringia, esposo de María Teresa de Austria, quien desde 21 de noviembre de 1740 fue consorte de su mujer. Como María Teresa el 13 de marzo de 1740 dio a luz a su hijo Francisco, en la primavera de 1740 el gran duque Francisco trataba de concentrar en sus manos los asuntos estatales. Por ejemplo, él fue que nombró al conde de Neipper a la cabeza de las tropas austriacas que, por fin, sufrieron derrota en la batalla de Molwitz. János BArTa 1ij., Mána Terizia, Budapest, 1988, págs. 58., 65.

${ }_{61}$ Instructiones, pág. 122.

62 Liż́r, op. cit., pág. 81.; En la bibliografia sólo Lázár se ocupa detalladamente de la política exterior de la regencia de Ana, pero él tampoco indica la fecha exacta de la alianza prusiano-rusa.

Hitpania, J.IX/2, nüm. 202 (1909) 565-586 
bargo, la regente Ana influida por Lynar y el marqués de Botta y «Sin escuchar y dar crédito a las palabras de Münnich y Ostermann' " ${ }^{63}$, anuló el acuerdo prusiano-ruso y se empeñó al lado de Austria. El comportamiento de Ostermann, tepresentante prominente de la orientación austriaca en la corte rusa tal vez se explicara que él conocía la mala situación financiera del estado ruso por eso intentó evitar una nueva guerra. Es decir, reconociendo los derechos de María Teresa de Austria, no quería ser arrastrado a una guerra ocurrida por intereses fundamentalmente ajenos.

Por otra parte, las citas ponen de manifiesto que España por su propio bien quería obtener la neutralidad de Rusia en la cuestión de la sucesión austriaca o, en caso más favorable, su adhesión al campo de las potencias antiaustriacas. Pues Felipe V, aludiendo al testamento de Carlos II, exigió la completa herencia de los Habsburgo ${ }^{64} \mathrm{y}$ veía una nueva posibilidad para validar sus intentos dinásticos, es decir, en esta coyuntura a su hijo Felipe adquirir dominio en Italia. Pata tealizar esto había oportunidad que María Teresa se veía obligada a retirar sus tropas de Milanesado.

En relación con las fuerzas de la política interior rusa eso significó que la victoria de la orientación francesa o el abandono de la alianza con Austria hubieran sido bien vistos por los responsables de la política exterior española. Pues la negación de Rusia a la petición de ayuda de Austria de todos modos habría reforzado el campo francés-español y Prusia frente a la agrupación británico-holandesa y Austria ${ }^{65}$ que estaba formándose y el 25 de junio de 1741 tomó forma de alianza ${ }^{65}$.

En este sentido, el principal fin diplomático del conde de Bena consistía en que tratara de conquistar la voluntad de Rusia como aliado o potencia neutral para los estados botbónicos. Con el fin de influir en la posición de los primeros políticos del estado ruso en la cuestión de la Pragmática Sanción, una serie de instrucciones dadas a Bena se refiere a los medios que el diplomático español podía emplear, según cupiera en la oportunidad y en las circunstancias. Eso nos demuestra la importancia de la opinión rusa para Madrid.

Para lograr sus objetivos diplomáticos, una de estas instrucciones a Bena fue la de proponer a Rusia un tratado comercial que desde mucho tiempo fue deseo de los zares. «Bien consideramos que la distancia que media entre Moscovia y estos Dominios y entre los que desea el Rey para el infante Don Felipe, del mismo modo que constituye a aquel Monarca sin un grande interés en nuestra alianza, nos hace no esperar el mayor de la suya; pero las ventajas del comercio, a que no poco se aplican los rusos desde la vida del Glorioso Piotr Alexéyevich, pueden compensar la diversión y garantía que nos ofrezcan ${ }^{67}$ \%.

63 LÀZÁr, op. cit., pág. 81.

64 Gonda - Niederhauser, A Habsburgok, Budapest, 1987, pág. 115.

65 Ibidem, pág. 116.

66 Ozanan, op. cit., pág. 627.

67 Instructiones, pág. 122.

Hicpania, LiX/2, núm. 202 (1999) 565-586 
Las ventajas de este comercio hispano-ruso para España se resumen y se explican en dos puntos. «Y por que comprendáis la principal máxima en que nos fundamos para desearle, tendréis entendido que consiste en dos principios: el primero, el de estimular a nuestros vasallos a que le emprendan en Moscovia, para no comprar de segunda manos los géneros que nos vienen de aquellos reinos, en que no se cifran pocas utilidades; y el segundo, el de que pierdan éstas y otras los ingleses y holandeses, que son los que disfrutan nuestro trato y los que más convierten estas mismas ganancias en nuevo perjuicio nuestro, acrecentando sus fuerzas, con que se hacen de enemigos que son, casi forzosos, los más considerables enemigos ${ }^{6 \eta_{7}}$.

Estos principios son los mismos que se escribieron en el Anteproyecto de acuerdo comercial de Francisco Perals (24 de enero 1724 ) ${ }^{69} \mathrm{y}$ en el del duque de Liria (junio o julio 1728) ${ }^{70}$. Si ponemos en parangón los párrafos respectivos de las Instrucciones a Bena con los proyectos de los años veinte, encontramos casi las mismas frases y el sistema de los argumentos en la cuestión de un contrato comercial -en cuanto a su consistencia - tampoco cambió en la segunda mitad del siglo 18.

Establecer un comercio directo con Rusia se reiteraba en los proyectos comerciales e instrucciones diplomáticas como principio primordial supuesto que «Con la incorporación de Ucrania y la conquista de Crimea Rusia y varios países occidentales podian empezar a realizar sus planes a largo tiempo para evitar la ruta inconfortable del Báltico cargada por derechos daneses, privilegios ingleses y dificultada por el control financial alemán» ${ }^{71}$. A través de un tráfico directo de mercancías se hubieran podido bajar los precios. $\mathrm{El}$ argumento que de esta manera España perjudicaría la potencia económica de Inglaterra y Holanda, entre las cuales a Inglaterra la consideraba como su principal enemigo, fue el principio segundo a firmar un acuerdo comercial hispano-ruso. Pues, en efecto, estas dos potencias controlaron la exportación rusa, sobre todo desde el acuerdo comercial ruso-inglés de 1734. Sin embargo, los intentos permanentes para establecer y mantener un comercio directo entre España y Rusia tenían pocos éxitos durante el siglo 18.

Con objeto de influir en la opinión rusa en la Pragmática Sanción, el conde de Bena podía recurrir también a otro medio, al de maniobrar con otras potencias 0 fuerzas. Esto significó, por una parte, la colaboración con los diplomáticos francés y prusiano en la corte zariana.

«En todos estos encargos podrá tener Francia no pequeña parte, si abrazare descubiertamente nuestras resoluciones, pero en tanto que no llegue este caso,

68 Instructiones, pág. 122.

69 Anteproyecto de acuerdo comercial, en Corpus Diplomático Hispano-Ruso, doc. 37, paigs. 72-79.; Según Krylova, Perrata. Véase: KRYLova op, cit. pág. 346.

70 Diario, págs. 241-244.; Despacho del Duque de Liria al Marqués de la Pav, en Corpus Diplomático Hispano-Ruso, doc. 50., págs. 110-113.

71 W. KirCHNer, Commercial relations between Russia and Europe 1400-1800, Bloomington, 1966, pág. 16.

Hiquania, L.IX/2, núm 202 (1999) 565-586 
o mientras que obrare de otra manera, os manejaréis con su Ministro cauta y precaucionadamente, pues aunque queremos que le tratéis con distinción, y como que nos conviene el que se persuadan todos a que es la más estrecha nuestra correspondencia con aquella Corona, en lo que no se engañarán, puede acaecer que en alguna o algunas de las ideas mencionadas se desunan nuestras respectivas máximas, y entonces sería dañoso el abtiros enteramente e importará cautelarse del mismo modo que con los Ministros más extraños o imparciales" ${ }^{72}$.

«Si fuere (como se dice) cierta la alianza de aquella Corona con el Rey de Prusia, os haréis parcial del Ministro de este Soberano, para sostener sus intereses, pues aunque hasta ahora no están ligados con los nuestros por tratado alguno, se deben contar como de una misma naturaleza, mientras no precediera ajuste sobre la conquista de la Iglesia ${ }^{73}$ y se mantuvieran sus atmas opuestas al Gran Duque [Francisco de Lotaringia - M.K.], en cuyo Estado, si algo se innovare, se os participará para vuestro gobierno" ${ }^{74}$.

La instrucción a Bena sobre el comportamiento confidencial pero no abierto con su colega francés se explica por la divergencia de los intereses españoles y franceses que eran cercanos pero no idénticos. Esta divergencia ya se manifestó en la Guerta de Sucesión de Polonia durante la cual Francia entabló negociaciones con Austria sin España y firmó con ella los preliminares de paz (3 de octubre de 1735) ${ }^{75}$. En la Guerra de Jenkins' Ear Fleury sólo después del éxito inglés contra Portobello (22 de noviembre de 1739) decidió ayudar de hecho a España ${ }^{76}$. Esos dejaron recuerdos amargos en Felipe $V$ en cuanto a la efectividad de la alianza francesa. La divergencia de intereses también se manifestó en la fase inicial de la Guerra de Sucesión de Austria. Francia "Aunque aceptase en principio favorecer las pretensiones de Felipe en Italia, las subordinaba a los acuerdos que debían firmarse entre Madrid y los otros pretendientes a la herencia austriaca — rey de Cerdeña y elector de Baviera - ..., ${ }^{77}$.

72 Instrucciones, pág. 124.

73 En Prusia había mucho más tolerancia religiosa que en otros reinos. Aunque el rey Federico I nombró un consejo para preparar la unificación entre la iglesia evangélica y la reformada (1703), el proyecto fracasó. Konrád SzÁN'Tó, A katolikus egybáz története, T. II, Budapest, 1988, pág. 248.; Frederico II en cuestiones religiosas dio muestras de su ilustración y tolerancia. Asi la frase «ajuste sobre la conquista de la Iglesia» tal vez se refiera a unas tendencias menos tolerables con los católicos que vivían en Prusia. La existencia de éstas se manifiesta en el cuento siguiente. Apenas subió al trono Federico II cuando sus ministros le preguntaron si quería mantener las escuelas para hijos católicos de soldados porque causaban «todas clases de inconveniencias». Federico II respondió: «Hay que tolerar todas las religiones...» Véase: Bernt ENGFL MANN, Poroszország. A lehetösêgek bazája, Budapest, 1986, pág, 116.

74 Instrucciones, pág. 122.

75 España fue aliado de Francia según el Primer Pacto de Familia ( 7 de noviembre de 1733). Sin embargo, Francia sóla entró en negociaciones con Austria (agosto de 1735). Véase: OzANAN, op. cit., págs. 614., 617.

76 Ilidem, págs. 624-625.

77 Ibidem, pág. 626.

Hispania, LIX/2, núm. 202 (1999) 565-580 
Como menciona también el documento mismo, la falta de la correspondencia oficial entre España y Prusia en esta época ${ }^{78}$ dificultó la colaboración hispano-prusiana. José Maria Sánchez Diana, conocedora de las relaciones hispano-prusianas escribe en su estudio que los contactos diplomáticos regulares entre los dos estados, diferentes en cuanto a su religión, se iniciaron precisamente en $1740^{77}$. En ésta aproximación, en la cual el afán era más fuerte en España que en Prusia, desempeñaron gran papel la personalidad de Federico II, luego su prestigio de estratega adquirido en la Guerra de Sucesión de Austria y la posibilidad de un tratado comercial entre los dos estados. Por último, pero no en último lugar, mencionamos un factor político que inspitó a España establecer vínculos diplomáticos más sólidos con Prusia: la existencia de una fuerte Prusia en las correlaciones de fuerzas de Europa significó la dualidad alemana y sus ventajas para los enemigos de Austria, entre ellos para España. Sin embargo, en 1741 Federico II se resistía cortésmente al acercamiento español, «... creyendo que la distancia que nos separa impedía dar efectividad suficiente a ningún acuerdo entre ambos países» ${ }^{80}$.

La maniobra con otras potencias o fuerzas, por otra parte, significó para Bena la manipulación con Suecia. Pues una de las instrucciones a Bena dice que siempre teniendo en cuenta los intereses de España- operara con las quebrajosas relaciones sueco-rusas, es decir, facilitara sus contactos tranquilos o, en caso contrario, obrata por el rompimiento entre ellos. «De suerte que si Moscovia se empeña a favor de la Pragmática Sanción, o en virtud de sus obligaciones con el Emperador difunto o de las influencias de los ingleses y holandeses, deberéis contribuir a que rompa con Suecia, activa o pasivamente, según cupiere el tramarlo; y si no solo no entra el Zar en los empeños de la Casa de Austria, sino que abraza los que contra ella fomentamos, o bien nos deja el campo libre para proseguirlos, habéis de trabajar entonces en apagar las disensiones con Suecia, procurando el sosiego y el ajuste, por que no causen sus disputas algún perjuicio a nuestras operaciones, pues aunque nos cae muy distante la guerra que pueden hacerse, suelen enlazarse de forma los acaecimientos, que sucede lo que con la llama, que se comunica de una a otra materia y pasa a veces donde menos se receló que llegase el incendio ${ }^{81}$ )》.

Por lo demás, la idea de manipular con Suecia para tener en jaque a Rusia no fue original, pues la diplomacia francesa empleaba este medio con regulari-

78 “Hasta 1781 no se consiguió el nombramiento de ministros respectivos.» Véase: José Matía Sánchez Diana, España y la política exterior de Federíco II de Prusia (1740-1786), en Hispania, T. XV (1955), pág. 216.; «El 13 de agosto de 1782 recibió Federico II al Embajador español,» Ibidem, pág. 220.; Sin embargo, según VolTEs Bou «En 1783, con don Simón de las Casas, España nombró su primer embajador en Berlín, y Prusia lo tuvo en Madrid con el conde de Nostitz por las mismas fechas.s Véase: Pedro VoLTEs Bou, Carlos MI y su tiempo, Ed. Juventud, S.A., Barcelona, 1975, pág. 219.

79 SÁNClEZZ DIANA, op. ait., pág. 194.

Bo VolTus Bou, op. cit.,pág. 219.

81 Instructiones, pág. 123. 
dad. Lo podía emplear porque desde la Paz de Nystadt (septiembre de 1721) no fue dificil despertar emociones antirusas en la corte sueca. Eso fue justificado por los acontecimientos posteriores cuando «Para ocupar a los rusos en otro lado, la diplomacia francesa consiguió una declaración de guerra de Suecia [24 de junio de $1741-\mathrm{M} . \mathrm{K} .{ }^{82}$, con el pretexto de que los rusos no respetaban el tratado de Nystad ${ }^{83}$ "), ni los derechos de la gran duquesa Isabel.

El documento puso en guardia a Bena contra cualquier iniciativa con Persia y Turquí, semejante a la propuesta con Suecia, a causa de la falta de la correspondencia oficial entre ellos. Para un caso extremo, la Secretaría de Asuntos Exteriores de España misma se encargó de presionar a los regentes de Rusia a través de su contacto indirecto con estas monarquías asiáticas. «No os sugetimos iguales maniobras con los Persas y Turcos, porque no consideramos iguales disposiciones que con los Suecos, no tenemos Ministros en aquellas Cortes como en la de Estocolmo y son muy distintas las relaciones de sus progresos hacia nuestros intereses, bien que en la diversión de las fuerzas pudiese ser una misma nuestra conveniencia. No obstante, en un caso extremo, influiréis lo que alcanzaréis y desde acá, con nuestro aviso, se buscará para los Turcos, a lo menos, el impulso que permita el manejo de Francia, o bien el Rey de las Dos Sicilias ${ }^{84}{ }_{7}$.

Consideramos de gran importancia que entre los medios empleables (propuesta de un contrato comercial, colaboración con los diplomáticos francés y prusiano, manipulación con Suecia, en un caso extremo, con Persia y Turquía) la Secretaría de Asuntos Exteriores tenía en cuenta la opasición de la política interior rusa. Contó con ella como «última apelación». «Aun sin estos recursos, encontraréis en la misma Moscovia los más ciertos para contenerla, sin no obstante la deposición del Duque de Curlandia ${ }^{85}$ y el castigo de los Dolgoruki ${ }^{86}$, hubiera quedado aún alguna semilla de aquellas alteraciones, no es imposible el cultivarla, para que brote y reverdezca; pero esta maniobra, que debe ser siempre un lance desesperado y como última apelación, no os la encargo para que la intentéis de forma que parezca acción vuestra e influjo nuestro, sino para que la gobernéis por un término que no descubra la intención ni empeñe a las resultas ${ }^{87}$ ).

82 LẢZȦR, op. cit., pág. 82.

83 Piatonov, op. cit., pág. 179.

84 Instrucciones, pág. 123.

85 Al caer Biron fue exiliado con su familia a Siberia. Más tarde lo rehabilitaron y regresó a Curlandia donde se murió en 1769. Véase: Paul DuKEs, The Making of Russian Absolutism 1613 1801, Longman, London and New York, 1990, pág. 119.

86 Después del fallecimiento de Pedro II (19 de enero de 1730) el Consejo Superior eleccionó al trono a la gran duquesa Ana de Curlandia estableciéndole ciertas condiciones para impedir la autocracía de los zares. Sin embargo, el intento del Consejo Superior fracasó y así restableciendo el poder autocrático del soberano ruso Ana y Biron ajustaron las cuentas con los Dolgorukiit, miembros del Consejo Superior. El edicto de la zarina Ana del 14 de abril de 1730 los sentencionó a exilio, encerrarse en claustro o a perder todos sus bienes. Véase: LAZÁr, op. cit., págs. 37-38.

87 Instrucciones, págs. 123-124.

Hippania, LIX/2, nürn. 202 (1999) 565-586 


\section{Resumen}

En resumen, podemos decir, que las citas presentadas bien demuestran que los responsables de la política exterior de España de los últimos años del reinado de Felipe V, por una parte, trataron de estudiar las principales tendencias de la política exterior de Rusia y, detrás de ellas, descubrir las fuerzas políticas interiores de la corte zariana. Por otra parte - lo que consideraron de mucha importancia en Madrid-, intentaron inclinar a su partido a unos desde los promotores de la política exterior rusa en el conflicto de la Pragmática Sanción. Después de un intervalo de diez años en las relaciones diplomáticas, por eso mismo buscó España contacto directo con el soberano ruso. Es decir, España ya antes de 1761 reaccionó a la aparición de Rusia como una gran potencia en Europa nombrando al conde de Bena a su ministro plenipotenciario a Rusia.

Pero el diplomático español nunca ha llegado a San Petersburgo y este hecho justifica que, a pesar de lo que bemos dicho antes, consideramos el año de 1761 como año en que se restablecieron las relaciones diplomáticas bispano-rusas. Pues para 1761 los soberanos respectivos no solamente nombraron a su representante diplomático sino este primer paso fue sucedido por la llegada de los ministros a su destino. Este segundo paso faltó en la misión de Bena como dice un documento: «[Este último] ${ }^{88}$ [Aleksei Pushkin - M. K.] fue designado en 1742 pero, no obstante, no llegó hasta la Corte española, quedándose en Holanda, por cuanto el mencionado Conde Delven, enviado aquí, [a San Petersburgo], se había quedado en París y continuaba viviendo allí sin que llegara [a Rusia]. Y puesto que al fin y a la postre la Corte española dejó en completo silencio la cuestión de intercambio de embajadores, ordenamos finalmente también que el gentilhombre de Cámara Pushkin regresara desde Holanda a Rusia. Posteriormente, el Conde Delven fue nombrado por su Gobierno Ministro ante la Corte polaca ${ }^{89}$ \%.

En el trasfondo de estos acontecimientos encontramos, por una parte, las luchas por el poder en la corte zariana en las cuales, por fin, la gran duquesa Isabel, hija de Pedro el Grande superó a los demás (25-26 de noviembre de 1741). Por otra parte, España y Rusia no se entendieron en la cuestión del reconocimiento del título de emperador de los zares ${ }^{00}$. Este desacuerdo nos ofrece la posibilidad de aclarar aquí la cuestión del tratamiento imperial porque en este terreno hay equivocaciones cronológicas en Ia bibliografia.

88 Haciéndose con el poder (25-26 de noviembre de 1741) la zarina Isabel I nombró a Aleksei Pushkin a la corte de España. Véase: Carta de Elisaveta Petronna a Felipe $V$ sobre el envio del chambelán Alexei Pushkin a la Corte de España en calidad de ministro plenipotenciario con fecha de 6 de febreto de 1742, en Corpus Diplomático Hispano-Ruso, doc. 56, págs. 125-126.

B) Rescripto, págs. 126-127.

90 UlIANITSKII, op. cit., págs. 152-153. (La referencia está mencionada por ALEKSÉEV, op. cit., pág. 186 , nota 75 ).

Hippania, LIX/2, núm. 202 (1999) 565-586 
El reconocimiento del titulo de emperador de los zares por parte de España

Dos historiadores famosos, Paul Duke y Riasanovsky escriben en sus obras sin ninguna explicación o referencia que España ya en 1745 reconoció el derecho de los zares a llevar el título de emperador ${ }^{91}$. Este gesto protocolario del rey español fue posterior al de las demás potencias europeas, pues Holanda y Prusia en 1722, Suecia en 1723, Dinamarca en 1724, Sajonia en 1733, Turquía en 1741, Austria e Inglaterra en 1742 y Francia en 1744 o 1745 hicieron lo mismo ${ }^{92}$.

Podría imaginarse que España, entonces aliado de Francia ${ }^{93}$, bajo la influencia francesa y a pesar de la falta de la correspondencia oficial hispanorusa, en 1745 reconociera el derecho de los zares a llevar el título de emperador. Sin embargo, documentos contemporáneos obviamente argumentan que entre los soberanos españoles Carlos III fue el primero que reconoció la exigeniza de los zares al titulo imperial. Eso fue el gesto a que se debió la posibilidad efectiva de renovar los contactos interestatales entre España y Rusia.

Resulta del primer documento que vamos a citar que el nuevo rey de España, Fernando VI no dio el tratamiento imperial a los soberanos rusos ni en 1746 ni más tarde y, de esta maneta, como constata el Rescripto de $1759, \mathrm{Ma}$ drid y San Petersburgo no sostenían ningún intercambio oficial de correspondencia.

«Posteriormente, el Conde Delven fue nombrado por su Gobierno Ministro ante la Corte polaca. Vos, que precisamente entonces os encontrabáis acreditado ante la Corte polaca, escribisteis en vuestro despacho de 5 de agosto de 1746 , que él, por orden de su Gobierno, os comunicó la no intención del actual Rey español de enviarnos una notificación acerca del fallecimiento de su padre, a causa de que [su] escrito anterior habia sido devuelto por nuestro Embajador en París por la falta en él del título de Emperador. El Rey español, su soberano, no ve ningún motivo para cambiar el antiguo título [de Zar] que se empleaba en el intercambio de correspondencia de sus antepasados con los nuestros, con mayor motivo aún, que no se ha firmado ningún acuerdo con la Corte española acerca de la utilización del título de Emperador. De esta manera, actualmente no sostenemos ningún intercambio oficial de correspondencia con la Corte española $94 \%$.

Este mismo documento explica que en San Petersburgo estaban dispuestos a restablecer los contactos diplomáticos con el rey de España. Para eso se veía una oportunidad en junio de 1759 porque a causa del estado grave del rey Fer-

91 DUKES, of. cit., pág. 130.; R1ASANOVSKY, op. cit., pág. 226.

92 DUKES, op. cit., pág. 130.; RIASANOVSKY op. cit., pág. 226. Quisiéramos completar la lista con la República Veneciana que para los primeros años del tercer decenio del siglo 18 reconoció el título de emperador de los zares. Véase: Relación de Moscovia por el Duque de Liria, en Colección de Escritores Castellanos por A. PAZ y MELIÁ, T. 87, Madrid, 1890, pág. 316.

93 El Segundo Pacto de Familia se firmó el 28 de octubre de 1743.

94 Rescriplo, pág. 127.

Hippania, LIX/2, núm. 202 (1999) 565-586 
nando VI el advenimiento del rey de Nápoles al trono español fue probable en un futuro cercano. Esto, en cuanto a la cuestión del título imperial de los zares, significó que en la corte zariana esperaban - y no sin fundamentos- un cambio en el comportamiento español, esperaban concretamente que a la negación tenaz de Felipe V y Fernando VI sucediera la afirmación del rey nuevo.

«Entre tanto, de todas partes nos llega la información confirmando las noticias sobre la mala situación de la salud del actual Rey español. En caso de su fallecimiento, al trono de España ascenderá por derecho de sucesión el Rey de Nápoles, quien, como es bien sabido, mantiene correspondencia con nosotros. No se sabe, sin embargo, si la va a continuar en lo sucesivo, cuando ascienda al trono español, puesto que las dificultades que arriba se expresan, y que atañen al título de Emperador, continúan sin resolverse con España hasta el presente. Es imprescindible recibir anticipadamente, utilizando la mediación amistosa de la Corte francesa, la seguridad del Rey de Nápoles sobre que, después de su advenimiento al trono español, a ejemplo del Emperador del Sacro Imperio Romano, del mismo Rey francés, y de casi todas las cortes reales, en sus escritos utilizará el título de Emperador de Rusia al igual que viene empleando hasta el presente [como] Rey de Nápoles. Por mi parte, el día cuatro, en una sincera conversación que sostuve con el Duque de Choiseul, le trasmití, en los términos apropiados al caso, la esperanza que sostenía Su Majestad de que Su Majestad Cristianísima no se négaría a prestar su ayuda en este asunto ... Por su parte, Choiseul me aseguró que su Majestad no negará su ayuda a Su Majestad Imperial en este asunto. Me figuro que sólo se podrá avanzar en tal cuestión después del fallecimiento de Su Majestad Católica y de la llegada al poder del Rey de Nápoles ${ }^{25} \%$.

Por fin, quisiéramos apoyar nuestra afirmación contraria a las de Duke y Riasanovsky en otra cita que también verifica que entre los reyes españoles Carlos III fue el primero quien dio el tratamiento de emperador al soberano de Rusia. Pues de la Instrucción al marqués de Almodóvar, ministro plenipotenciario a Rusia, escrita veinte años más tarde que las Instrucciones al conde de Bena se pone de manifiesto que esta cuestión protocolaria se quedó sin resolución hasta la subida de Carlos III al trono español. Él entre sus primeras medidas que tomó, todavía desde Nápoles, es decir, antes de su salida a España (6 de octubre de 1759) ${ }^{96}$ escribió a la zarina, dándole el tratamiento de emperatriz.

«Bien notorio es que ha estado la España muchos años sin correspondencia ni trato con la córte de Rusia, y aunque puede haber contribuido á ello la falta de asunto que lo exigiese, no hay duda en que lo ha motivado principalmente la dificultad que encontraton el Rey mi muy venerado padre y el Rey mi muy amado hermano, en dar el título de Majestad Imperial á la Emperatriz de aquellos vastos dominios. Luego que por disposición del Altísimo cayó sobre mis sienes la corona de España, escribí desde Nápoles con este motivo á la Zarina,

95 Ibidem, pág. 127.

96 Voutes Bou, op. cit., pág. 60.

Hispania, LIX/2, núm 202 (1999) 565-586 
dándola generosamente el tratamiento de Imperial, tanto por considerar que no podria seguirse ningun perjuicio á mi decoro y dignidad, en reconocerla del mismo modo que la habrán reconocido los demás potentados de Europa, con especialidad mi primo el Christianísimo, como porque pesando las ventajas teales que produciría con el tiempo á mis Reinos y vasallos, la correspondencia que los de aquel Imperio con las ningunas que resultarian de sostener con teson un punto que es de pura formalidad, no se veia motivo para dudar en la eleccióñ ${ }^{97}$.

\section{EPÍLOGO}

Después que la España de Carlos III había reconocido a nivel protocolario también la posición de gran potencia de Rusia ya no se dificultó el restablecimiento de las relaciones diplomáticas hispano-rusas. Sin embargo, estas relaciones para ambos estados, principalmente para Rusia constituyeron la parte periférica del sistema de sus relaciones internacionales. En el siglo 18 «La política de acercamiento del gobierno español respecto al ruso registra su época dorada.... ${ }^{98}$ sólo entre 1780 y 1787 cuando la dinámica de las relaciones internacionales creó una situación que desde España exigió tener vinculaciones más estrechas con Rusia para asegurar y mantener el equilibrio continental favorable a sus intereses estratégicos y diplomáticos, principalmente en la región del Atlántico y también en Europa.

97 De la Instrucción que llevó el Marqués de Almodóvar cuando fué de Ministro Plenipotenciario à Rusia fechada en Buen Retito á 9 de Marzo de 1761, en Correspondencia, pág. 9.

8 Hernández Franco, op. cit., pág. 137.

Hipania, LIX/2, nim. 202 (1999) 565-586 